\title{
PENGANEKARAGAMAN PRODUK OLAHAN PISANG DIDESA PENITI LUAR KABUPATEN MEMPAWAH KALIMANTAN BARAT
}

\author{
Diversification of the Rural Banana Processed Products at Desa Peniti Luar Mempawah \\ Regency West Kalimantan
}

\author{
Lamria Mangunsong ${ }^{1)}$, Sari Zawitri ${ }^{1)}$, Susana ${ }^{1)}$ \\ Teknologi Pengolahan Hasil Perkebunan Politeknik Negeri Pontianak ${ }^{1)}$ \\ lamriasanopti@yahoo.com
}

\begin{abstract}
The activity of Community Service (PKM) was implemented at Desa Peniti Luar Siantan District Mempawah Regency. The aims of its were to give information knowledge and skills and also technology to diversified banana which was processed prospect food product, also to grow spirit of enterpreneurship PKK'group as an advanced and autonomous partners in knowledge, expertise, and skill whom processed local potential of local agricultural products into various refined products are creative, nutritious and high-value sales efforts to increase the income of local communities and support government programs in food security. Method of the activities that was implemented is the Technology Transfer (science and technology) and Entrepreneurship ( Entrepreneurship ) form Submission of materials appropriate technology based banana, explanation of the equipment and materials used during production, training and technical assistance to the partners in production, entrepreneurial training and marketing strategies include: packaging, price, promotion and distribution as well as the evaluation of the results of activities.The results of this PKM activity can be accepted by the community which can be shown by the enthusiasm of participants, other than that trainees have the ability to practice their processed products with good and interesting, so they are keen to make his own and opened a small business to supplement the family income.
\end{abstract}

Keywords : banana, entrepreneurship, technology transfer (science and technology), the PKK group, prospectively

\begin{abstract}
ABSTRAK
Kegiatan pengabdian kepada masyarakat ini akan dilaksanakan di desa Peniti Luar Kecamatan Siantan Kabupaten Mempawah. Adapun tujuan dari PPM ini adalah : memberikan informasi pengetahuan dan ketrampilan IPTEKS diversifikasi pisang menjadi produk olahan pangan yang prospektif serta membangun jiwa kewirausahaan di kalangan kelompok PKK sebagai mitra yang belum produktif menjadi mitra yang lebih maju dan mandiri dalam pengetahuan, keahlian dan keterampilan dalam mengolah potensi lokal hasil pertanian setempat menjadi berbagai produk olahan yang kreatif, bernutrisi dan bernilai jual tinggi upaya untuk meningkatkan pendapatan masyarakat setempat dan mendukung program pemerintah dalam ketahanan pangan. Metode Kegiatan yang akan dilaksanakan adalah Transfer Teknologi (Ipteks) dan Kewirausahaan (Entrepreneurship) berupa Penyampaian materi Teknologi tepat guna berbasis pisang, penjelasan peralatan dan bahan yang digunakan selama produksi, pelatihan dan bimbingan teknis terhadap mitra dalam berproduksi, pelatihan kewirausahaan dan strategi pemasaran meliputi: pengemasan, harga jual, promosi dan distribusi serta evaluasi hasil kegiatan. Hasil kegiatan PKM ini dapat diterima oleh masyarakat hal ini dapat ditunjukkan dengan antusiasnya peserta pelatihan, selain itu peserta pelatihan memiliki kemampuan untuk mempraktekkan hasil olahannya dengan baik dan menarik sehingga mereka tertarik untuk membuat sendiri dan membuka usaha kecil untuk menambah income pendapatan keluarga
\end{abstract}

Kata kunci : pisang, entrepreneurship, transfer teknologi (ipteks), kelompok PKK. 


\section{PENDAHULUAN}

Pisang (Musa paradisiaca) merupakan bahan pangan sumber karbohidrat selain itu juga mengandung vitamin dan mineral. Penerimaan konsumen terhadap komoditas tersebut masih terus ditingkatkan dengan cara memperbaiki pengelolaan, efisiensi pengolahan dan diversivikasi pengolahan lebih lanjut untuk menigkatkan nilai tambah dari komoditas ini. Dengan demikian, dapat dikembangkan industri berbasis pisang yang kokoh dengan pengembangan produk utama, dan produk samping dari pisang. Usaha untuk mengembangkan agroindustri berbasis pisang yang mengutamakan produk olahan bernilai ekonomi tinggi dan memaksimalkan nilai ekonomi produk sampingnya akan memberi nilai tambah yang nyata bagi peningkatan pendapatan pelaku agroindustri dan pertumbuhan ekonomi wilayah. Salah satu wilayah Kalimantan Barat yang masyarakatnya mengusahakan pertanaman pisang adalah desa Peniti luar Kecamatan Siantan Kabupaten Mempawah.

Kecamatan Siantan merupakan salah satu kecamatan yang berada di wilayah kabupaten Mempawah Propinsi Kalimantan Barat. Luas wilayah kecamatan Siantan $160,30 \mathrm{Km}^{2}$, terdiri dari lima desa (Wajok Hulu,Wajok Hilir, Jungkat, Sungai Nipah dan Peniti Luar) dengan jumlah penduduk sebanyak 13.571 jiwa

Desa Peniti Luar merupakan salah satu desa yang berada di Kecamatan Siantan Kabupaten Mempawah Kalimantan Barat dengan luas wilayah 2.954,25 Ha terdiri dari 3 dusun yaitu dusun Karya Bakti, Panca Bakti dan Taruna Bakti. Secara geografis, batas wilayah desa Peniti Luar bagian Utara berbatasan dengan desa Sungai Burung Kecamatan Segedong, bagian Selatan berbatasan dengan desa Sungai Nipah Kecamatan Siantan, bagian Barat berbatasan dengan laut Natuna dan bagian Timur berbatasan dengan desa Peniti Dalam I Kecamatan Segedong.
Jumlah penduduk di desa Peniti Luar sebanyak 2.737 jiwa (laki-laki berjumlah 1.488 jiwa dan perempuan berjumlah 1.249 jiwa) dengan matapencaharian penduduk sebagian besar bekerja sebagai petani pisang jenis kepok.Potensi lahan dengan jenis tanah Olivial dan gambut sangat cocok untuk tanaman pisang. Sampai saat ini desa Peniti Luar merupakan salah satu daerah penghasil pisang di kecamatan Siantan.

Berdasarkan hasil informasi yang diperoleh dari Bapak Burhan selaku Sekretaris desa bahwa pada umumnya pisang dengan (varietas Kepok yang dominan) dipasarkan dalam bentuk segar dengan harga Rp. 2000/kg. Pola rantai pasokan yang berkembang pada pemasaran pisang sangat beragam dan biasanya petani menjual kepada pembeli yang menawarkan harga paling menguntungkan.

Pisang yang dihasilkan oleh Desa Peniti Luar Kecamatan Siantan belum dikembangkan dan dimanfaatkan dengan baik. Hasil pertanian yang berasal dari daerah ini masih ditangani secara konvensional yaitu mengolah pisang dalam bentuk pisang rebus, pisang goreng, kolak dan keripik pisang. Diversifikasi hasil panen pisang yang masih terbatas mengakibatkan keuntungan yang diperolah petani belum optimal.

Banyaknya pisang didesa Peniti Luar memberi potensi dan peluang usaha yang sangat menjanjikan bagi masyarakat. Salah satu upaya untuk mengembangkan potensi tanaman pisang dapat dilakukan melalui upaya diversifikasi produk berbasis pisang menjadi makanan yang bergizi, awet, enak, bernilai ekonomis dan disenangi masyarakat dengan memanfaatkan hampir semua bagian tanaman pisang yaitu dari daging buah sampai pada bagian limbahnya.

Sasaran Kegiatan PPM ini ditujukan pada kelompok ibu PKK sebagai Mitra yang di ketuai oleh ibu Asnayati. Sebagian besar ibu PKK di Desa Peniti Luar merupakan istri petani pisang .Aktifitas kegiatan Ibu PKK dilakukan sebulan sekali (minggu pertama) di rumah ibu KADES, dengan kegiatan rutin adalah Arisan dan pengajian dan posyandu. 
Pengetahuan ibu PKK tentang aplikasi teknologi pengolahan khususnya pisang masih terbatas sehingga upaya menjadikan komoditi tersebut sebagai pangan olahan tidak banyak diminati. Terbatasnya pada modal, teknik pengemasan dan pemasaran merupakan kendala bagi kelompok mitra untuk melakukan usaha produksi. Salah satu upaya untuk mengembangkan potensi pisang dapat dilakukan melalui upaya diversifikasi pengolahan produk olahannya yaitu dari daging buah sampai pada bagian limbahnya menjadi produk olahan pangan. Diversifikasi produk olahan dipilih dengan memperhatikan aspek ekonomi dan tingkat pendidikan petani dan ibu PKK di desa Peniti Luar. Teknologi pengolahan untuk membuat produk hilir pisang dan labu kuning merupakan teknologi sederhana, sehingga mudah dimengerti dan dilaksanakan oleh kelompok tani dan ibu PKK. Sementara itu dari aspek ekonomi produk tersebut merupakan produk olahan pangan yang prospektif untuk dikembangkan menjadi alternative usaha kecil. Oleh karena itu dengan dibarengi kegiatan/ program Entrepreneurship maka produk tersebut dapat dipasarkan yang pada giliranya dapat memberikan income/penghasilan tambahan bagi masyarakat mitra.

Kegiatan pengabdian kepada masyarakat ini bertujuan : 1) memberikan informasi pengetahuan dan ketrampilan IPTEKS diversifikasi pisang menjadi produk olahan pangan yang prospektif serta membangun jiwa kewirausahaan di kalangan kelompok PKK sebagai mitra yang belum produktif menjadi mitra yang lebih maju dan mandiri dalam pengetahuan, keahlian dan keterampilan dalam mengolah potensi lokal hasil pertanian setempat menjadi berbagai produk olahan yang kreatif, bernutrisi dan bernilai jual tinggi dalam upaya peningkatan sumber daya manusia, 2). Memberikan pelatihan dan pembimbingan keterampilan, keahlian dan memotivasi masyarakat Desa Peniti Luar Kecamatan Siantan dalam memanfaatkan pisang menjadi produk makanan sebagai alternatif usaha kecil untuk meningkatkan taraf hidup masyarakat, 3). Menumbuhkan jiwa kewirausahaan dan kreatifitas mitra yang dapat dikembangkan dan diciptakan dari pengembangan potensi sumber daya lokal yang dapat diukur dengan terbentuknya kelompok usaha kecil produk olahan pisang.

\section{METODE PENELITIAN}

\section{Alat dan bahan}

Alat yang digunakan untuk olahan produk pisang (tepung pisang, jaring-jaring pisang, cookies, bolu kukus dan nugget jantung pisang) meliputi : kompor gas, oven, blender, mixer, loyang aluminium, baskom, pisau, dandang, slicer, kuali, sendok penggoreng dan pengiris, ayakan, cetakan kue.

Sedangkan bahan yang digunakan untk olahan pisang meliputi : pisang, tepung terigu, soda, telur, metega, susu, vanili, aneka rasa (barbeque, keju, jagung, balado), keju, masako, minyak goreng

\section{Metode pelaksanaan}

Program Pengabdian Kepada Masyarakat ini akan ditujukan kepada kelompok PKK dengan Metode Transfer Teknologi (Ipteks) diversifikasi pisang menjadi produk pangan dan Kewirausahaan (Entrepreneurship) dengan memberikan penyampaian materi dan demonstrasi. Adapun langkah-langkah kegiatan IPTEK yang akan disampaikan kepada masyarakat adalah:

1. Penyusunan program kerja. Penyusunan program kerja ini dimaksudkan agar kegiatan yang dilaksanakan dapat berjalan dengan baik, teratur, lancar dan terarah misalnya cara penyampaian informasi, pemberian materi IPTEK, cara pendemonstarsian yang akan dilakukan supaya masyarakat dapat dengan mudah memahaminya.

2. Penyusunan modul pelatihan olahan pisang

3. Persiapan sarana dan prasarana pelatihan. 
4. Memberikan penjelasan dan pengetahuan kepada masyarakat dengan menyampaikan materi yang berkaitan dengan : Pengolahan Daging buah pisang dan bonggol pisang menjadi tepung sebagai bahan subtitusi tepung terigu untuk pembuatan cookies, jaring jaring pisang aneka rasa, bolu kukus, dan nugget

5. Melakukan tanya jawab dan diskusi. Setelah melakukan kegiatan penyampaian materi teknologi (IPTEKS), peserta diberi kesempatan untuk mengajukan pertanyaan terhadap materi yang kurang dimengerti atau kurang jelas. Setelah paham dengan teori yang disampaikan langkah selanjutnya adalah melakukan pelatihan olahan pisang

6. Pelatihan kewirausahaan bagi masyarakat mitra

7. Tahap Monitoring. Monitoring dilakukan secara intensif oleh tim pelaksana setiap kegiatan berlangsung untuk memastikan agar pelaksanaan kegiatan dapat berjalan sesuai rencana.

8. Tahap Evaluasi dilakukan sejalan dengan monitoring, sehingga jika ada kendala akan segera diselesaikan . Evaluasi dilakukan setiap tahap kegiatan, dengan menggunakan lembar Quesioner yang akan dibagikan kepada peserta pelatihan sebelum dan setelah kegiatan. adapun rancangan evaluasi memuat uraian bagaimana dan kapan evaluasi akan dilakukan, kriteria, indikator pencapaian tujuan, dan tolok ukur yang digunakan untuk menyatakan keberhasilan dari kegiatan yang dilakukan.

\section{HASIL DAN PEMBAHASAN}

\begin{tabular}{ccc}
\multicolumn{2}{c}{ Pelaksanaan Kegiatan PKM ini } \\
dilakukan dengan cara memberikan
\end{tabular} pengolahan pisang pada peserta pelatihan dengan membentuk kelompok kecil (setiap kelompok terdiri dari 7 orang) dengan maksud agar metode kegiatan PKM bisa dipahami dan dimengerti dengan jelas

Hasil Evaluasi yang dilakukan tim pada kegiatan PPM ini dengan melibatkan mitra (ibu PKK). Hasil evaluasi terdiri dari evaluasi terhadap pelaksanaan program (kegiatan PPM secara menyeluruh) dan evaluasi terhadap produk yang dihasilkan menggunakan lembar Quesioner yang akan dibagikan kepada peserta pelatihan sebelum dan setelah kegiatan. Secara rinci hasil evaluasi dapat diuraikan pada tabel di bawah ini.

Tabel 1. Evaluasi Pelaksanaan Kegiatan

\begin{tabular}{lll}
\hline No & \multicolumn{1}{c}{ Kriteria Kegiatan } & \multicolumn{1}{c}{ Tolak Ukur } \\
\hline 1. & Pelaksanaan pelatihan & $\begin{array}{l}\text { Sesuai jadwal yang telah disepakati } \\
\text { bersama }\end{array}$ \\
\hline 2. & Kehadiran peserta pelatihan & Minimal peserta 70\% hadir \\
\hline 3. & Keaktifan peserta pelatihan (antusiasme & $\begin{array}{l}\text { Peserta terlihat antusias mengikuti } \\
\text { pelatihan }\end{array}$ \\
peserta) & $\begin{array}{l}\text { Instruktur mempraktikkan cara olahan } \\
\text { daging pisang dan jantung pisang }\end{array}$ & $\begin{array}{l}\text { Peserta secara berkelompok mampu } \\
\text { membuat olahan pisang sesuai } \\
\text { meliputi : membuat tepung pisang sebagai } \\
\text { kriteria yang diharapkan }\end{array}$ \\
& $\begin{array}{l}\text { bahan pembuatan cookies, bolu kukus, } \\
\text { jaring jaring pisang dengan variasi bentuk, }\end{array}$ \\
pisang dan variasi rasa, nugget jantung & \\
sederhana. &
\end{tabular}


Sedangkan Target luaran PPM yang telah dapat tergambar pada Tabel dibawah ini : dicapai selama kegiatan ini dilaksanakan

Tabel. 2. Target luaran PPM di Desa Peniti Luar

\begin{tabular}{|c|c|c|c|}
\hline \multirow{2}{*}{ Kegiatan } & \multicolumn{2}{|c|}{ Indikator Kinerja } & \multirow{2}{*}{ Luaran } \\
\hline & Base line & Target & \\
\hline $\begin{array}{l}\text { Pelatihan } \\
\text { motivasi dan } \\
\text { kewirausahaan }\end{array}$ & $\begin{array}{l}\text { 1. Tingkat motivasi mitra } \\
\text { untuk meningkatkan } \\
\text { perekonomi keluarga } \\
(20 \%) \\
\text { 2. Tingkat keinginan } \\
\text { mitra untuk menjadi } \\
\text { wirausaha }(20 \%)\end{array}$ & $\begin{array}{l}\text { 1. Peningkatan motivasi } \\
\text { mitra untuk } \\
\text { meningkatkan } \\
\text { perekonomi keluarga } \\
(70 \%) \\
\text { 2. Peningkatan keinginan } \\
\text { mitra untuk menjadi } \\
\text { wirausaha }(75 \%) \\
\end{array}$ & \\
\hline $\begin{array}{l}\text { Pelatihan } \\
\text { Pembuatan } \\
\text { Produk }\end{array}$ & $\begin{array}{l}\text { Tingkat keterampilan mitra } \\
\text { dalam mengolah produk } \\
\text { olahan pisang }(10 \%)\end{array}$ & $\begin{array}{l}\text { Peningkatan keterampilan } \\
\text { mitra dalam mengolah } \\
\text { produk olahan pisang }(90 \%)\end{array}$ & $\begin{array}{l}\text { tepung pisang, } \\
\text { cookies, bolu } \\
\text { kukus, jaring- } \\
\text { jaring pisang } \\
\text { aneka rasa, } \\
\text { nugget jantung } \\
\text { pisang }\end{array}$ \\
\hline $\begin{array}{l}\text { Evaluasi akhir } \\
\text { materi dan } \\
\text { evaluasi } \\
\text { keterampilan } \\
\text { olahan pisang }\end{array}$ & $\begin{array}{l}\text { 1. Kemajuan dalam } \\
\text { pemahaman materi } \\
\text { motivasi dan } \\
\text { kewirausahaan }(20 \%) \\
\text { 2. Kemajuan dalam } \\
\text { keterampilan olahan } \\
\text { pisang }(10 \%)\end{array}$ & $\begin{array}{l}\text { 1. Peningkatan kemajuan } \\
\text { dalam pemahaman } \\
\text { materi }(90 \%) \\
\text { 2. Peningkatan } \\
\text { keterampilan mitra dalam } \\
\text { olahan pisang }(90 \%)\end{array}$ & \\
\hline $\begin{array}{l}\text { Pemantauan } \\
\text { khusus untuk } \\
\text { keberlanjutan } \\
\end{array}$ & $\begin{array}{l}\text { Keinginan untuk terus } \\
\text { berwirausaha di industri } \\
\text { olahan pisang }(20 \%)\end{array}$ & $\begin{array}{l}\text { Tingkat keinginan untuk } \\
\text { terus berwirausaha di } \\
\text { industri olahan pisang }(90 \%)\end{array}$ & \\
\hline
\end{tabular}

Berdasarkan hasil evaluasi dan indikator keberhasilan : Kegiatan PKM ini mendapatkan respon positif dari masyarakat. Hal ini terlihat dari kehadiran masyarakat dan keaktifan masyarakat dalam mendengarkan penjelasan tentang cara pengolahan diversifikasi pisang menjadi makanan yang enak, bergizi dan bernilai ekonomis. Selain itu pada sesi tanya jawab peserta ibu PKK sangat bersemangat dan sangat antusias mengetahui teknik pengolahan, pengemasan dan kewirausahaan. Adanya Kemauan Masyaakat / ibu PKK di desa Peniti Luar Kecamatan Siantan Kabupaten Mempawah dalam menerima inovasi baru. Hal ini terlihat dari antuasias ibu PKK dalam menerima pengetahuan dan ketrampilan tentang pemanfaatan bagian tanaman pisang menjadi makanan bergizi dan fungsinya bagi kesehatan. Dan Masyarakat ibu PKK di desa Peniti Luar Kecamatan Siantan Kabupaten Mempawah telah terampil dalam mengolah pisang: daging pisang diolah menjadi tepung pisang, cookies, bolu kukus, jaring-jaring pisang aneka rasa sedangkan limbahnya berupa jantung pisang diolah menjadi nugget.

Beberapa hasil Quisioner penilaian peserta terhadap produk olahan pisang diperoleh hasil sebagai berikut: 
a. Penampilan dari tepung pisang, cookies, bolu kukus, jaring-jaring pisang aneka rasa sedangkan limbahnya berupa jantung pisang diolah menjadi nugget, diperoleh penilaian : Menarik

b. Tepung pisang, cookies, bolu kukus, jaring-jaring pisang aneka rasa sedangkan limbahnya berupa jantung pisang diolah menjadi nugget yang kita hasilkan mempunyai nilai jual

c. Bahan baku yang diperlukan untuk pembuatan tepung pisang, cookies, bolu kukus, jaring-jaring pisang aneka rasa sedangkan limbahnya berupa jantung pisang diolah menjadi nugget dapat diperoleh dengan mudah

d. Proses pembuatan tepung pisang, cookies, bolu kukus, jaring-jaring pisang aneka rasa sedangkan limbahnya berupa jantung pisang diolah menjadi nugget mudah untuk dilaksanakan/dibuat sendiri

e. Sebagian Besar Masyarakat Mitra tertarik untuk membuat sendiri dan membuka usaha kecil setelah adanya pelatihan ini

\section{KESIMPULAN DAN SARAN}

\section{Kesimpulan}

1. Penerapan pengetahuan dan teknologi tentang diversifikasi pisang dari daging buah dan limbahnya sangat perlu dilakukan di Desa Peniti Luar Kecamatan Siantan Kabupaten Mempawah guna memanfaatkan potensi alam yang ada di daerah tersebut.

2. Pisang merupakan komoditas yang cukup berpeluang untuk dikembangkan di Desa Peniti Luar untuk dijadikan produk olahan pangan yang enek, bergizi dan bernilai ekonomis

3. Masyarakat Desa Peniti Luar (Ibu PKK sangat antusias dalam menerima IPTEK pengolahan pisang menjadi produk olahan yang bernilai ekonomis. Hal ini dapat terlihat peserta PPM sangat terampil dalam membuat produk.

\section{Saran}

Kegiatan Pengabdian Kepada Masyarakat perlu adanya pembimbingan dan pendampingan agar dapat terus dilakukan secara kontinyu dan berkesinambungan sehingga pengetahuan dan ketrampilan serta semangat yang tinggi bagi masyarakat di Desa Peniti Luar dapat lebih meningkat untuk terus mengembangkan usahanya

\section{DAFTAR PUSTAKA}

Anomin, 2014. Profil Desa Kabupaten Mempawah.

Sawit, M.H. 2000. Arah Pembangunann Pangan dan Gizi. Makalah pada Diskusi Round Table Peningkatan Ketahanan Pangan. Departemen Pertanian. Jakarta.

Suryana, A., 2001. Kebijakan Ketahanan Pangan. Yogyakarta : Prosiding Seminar Ketahanan Pangan.

Widowati, S., Suismono, Suarni, Sutrisno dan O. Komalasari. 2002. Petunjuk Teknis Proses Pembuatan Aneka Tepung dari Bahan Sumber Karbohidrat Lokal. Balai Penelitian Pascapanen Pertanian.

Winarno, F.G. 2000. Potensi dan Peran Tepung-Tepungan bagi Industri Pangan dan Program Perbaikan Gizi. Makalah pada Sem Nas Interaktif: Penganekaragaman Makanan untuk Memantapkan Ketersediaan Pangan. Jakarta. Oktober 2000. 